Bull. Mater. Sci., Vol. 14, No. 1, February 1991, pp. 35-41. (C) Printed in India.

\title{
Thermomechanical ageing (TMA) of 2014 aluminium alloy for aerospace applications
}

\author{
S SINGH and D B GOEL \\ Department of Metallurgical Engineering, University of Roorkee, Roorkee 247667 , India \\ MS received 4 June 1990; revised 13 February 1991 \\ Abstract. Various thermomechanical ageing (TMA) treatments for 2014 Al-alloy have \\ been developed which include partial peak ageing, warm rolling and further ageing to peak \\ hardness at $160^{\circ} \mathrm{C}$. Electron microscopic studies reveal that the TMA treatments affect \\ substantially the ageing characteristics. The TMA-Ib treatment yields finest $\theta^{\prime}$ needles \\ having longitudinal dimensions of $\sim 400 \AA$. TMA treatment leads to precipitate- \\ dislocation network of different magnitudes. Among the TMA treatments, the TMA IIb \\ treatment results in thickest precipitate-dislocation tangles. In addition to $\theta^{\prime}$, two types of \\ dispersoids $\mathrm{Al}_{4} \mathrm{CuMg}_{5} \mathrm{Si}_{4}$ and $\mathrm{Al}_{12}(\mathrm{Fe}, \mathrm{Mn})_{3} \mathrm{Si}$ have been observed. The density or \\ concentration of these dispersoids is drastically reduced due to TMA treatments. Thus an \\ optimum TMA treatment i.e. TMA-Ilb has been developed which results in a significant \\ improvement in the mechanical properties of 2014 Al-alloy.
}

Keywords. Thermomechanical ageing; 2014 aluminium alloy.

\section{Introduction}

The 2014 Al-alloy has a nominal composition: $4.40 \mathrm{Cu}, 0.40 \mathrm{Mg}, 0.80 \mathrm{Mn}, 0.80 \mathrm{Si}$ (Wt.\%) and $\mathrm{Fe}$ as impurity element. Although this alloy has its own importance in the aircraft industry due to high hardness and high strength at room temperature, its effective application is significantly hampered because of the poor dynamic properties like fatigue strength and fracture toughness and tensile properties at elevated temperatures. It has been reported by several workers (Ryum 1969; Lipsitt and Sargent 1970; Lipsitt 1971; Pattanaik et al 1972) that by thermomechanical ageing (TMA) treatment it is possible to develop a dislocation substructure which can withstand the effect of elevated temperatures without much loss in hardness and strength. The results reported in literature on the influence of TMA treatments on fatigue properties of this alloy were not consistent (Di Russo et al 1973; Malakondiah and Rama Rao 1977; Thompson and Levy 1977). As far as the fracture toughness is concerned the presence of dispersoids/inclusions is reported to be detrimental (Tanaka et al 1970; Hahn and Rosenfield 1975; Rack and Krenzer 1977; Thompson and Levy 1977; Santner 1978). The combined influence of dispersoids and the microstructure developed as a result of TMA treatments, however, has not been studied systematically to date. The present investigation has, therefore, been undertaken to explore the best combination of thermal and mechanical treatments i.e. to develop an optimum TMA treatment, which may eliminate or minimize the density of dispersoids and modify suitably the microstructure so as to cause an overall improvement of primary as well as secondary mechanical properties. 


\section{Experimental}

The alloy used in this investigation was prepared from $\mathrm{Al}$ of $99 \cdot 70 \%$ purity and $\mathrm{Cu}$, $\mathrm{Si}, \mathrm{Mn}$ and $\mathrm{Mg}$ were of $99.90 \%$ purity. Melting was carried out in electrical resistance furnace. Before preparing the final alloy, a master alloy of $\mathrm{Al}-33 \% \mathrm{Cu}$ was prepared by melting $\mathrm{Cu}$ and adding $\mathrm{Al}$ to raise the composition to the eutectic point. The alloy thus prepared was homogenized at $500^{\circ} \mathrm{C}$ and hot-rolled at $425^{\circ} \mathrm{C}$ to desired cross-sections. The various TMA treatments given to the alloy under investigation are shown schematically in table 1 . Hardness, tensile strength, fatigue and fracture toughness were measured after each TMA treatment. TEM and SEM were studied to understand the effect of various TMA treatments on structural parameters which affect the mechanical properties. Table 1 shows that the alloy was subjected to a maximum of $20 \%$ deformation before final ageing as in TMA-Ib and TMA-IIb. Attempts to deform the samples beyond $20 \%$ caused cracking.

Table 1. Schematic details of TMA treatments.

\begin{tabular}{|c|c|c|}
\hline $\begin{array}{l}\text { Treatment } \\
\text { designation }\end{array}$ & Schematic representation & Details of treatment \\
\hline $\begin{array}{l}\text { As Quenched } \\
\text { (AQ) }\end{array}$ & b) & $\begin{array}{l}\text { a. Solution treatment at } 500^{\circ} \mathrm{C} \text { for } 1.50 \mathrm{hrs} \\
\text { b. Quench in water }\end{array}$ \\
\hline Peak aged (PA) & $\begin{array}{lll}\mathrm{c} & \mathrm{d} \\
& \end{array}$ & $\begin{array}{l}\text { a. As above } \\
\text { b. As above } \\
\text { c. Peak ageing at } 160^{\circ} \mathrm{C} \\
\text { d. Quench in water }\end{array}$ \\
\hline TMA Ia & $\begin{array}{l}a \\
b \\
c_{d} M_{d}\end{array}$ & $\begin{array}{l}\text { a. As above } \\
\text { b. As above } \\
\text { c. } 25 \text { pct preageing at } 160^{\circ} \mathrm{C} \text { (up to } 73 \mathrm{VHN} \text { ) } \\
\text { d. } 10 \text { pct warm rolling at } 160^{\circ} \mathrm{C} \\
\text { e. Final ageing at } 160^{\circ} \mathrm{C} \text { to peak value } \\
\text { f. Quench in water }\end{array}$ \\
\hline TMA Ib & $\mathrm{c}_{\mathrm{d}} \mathrm{e}_{f}$ & $\begin{array}{l}\text { a. As above } \\
\text { b. As above } \\
\text { c. } 25 \text { pct preageing at } 160^{\circ} \mathrm{C} \\
\text { d. } 20 \text { pct warm rolling at } 160^{\circ} \mathrm{C} \\
\text { e. Final ageing at } 160^{\circ} \mathrm{C} \text { to peak value } \\
\text { f. Quench in water }\end{array}$ \\
\hline TMA Ila & $\mathrm{M}_{\mathrm{d}} \mathrm{M}_{\mathrm{f}}$ & $\begin{array}{l}\text { a. As above } \\
\text { b. As above } \\
\text { c. } 50 \text { pet preageing at } 160^{\circ} \mathrm{C} \text { (up to } 87 \text { VHN) } \\
\text { d. } 10 \text { pct warm rolling at } 160^{\circ} \mathrm{C} \\
\text { e. Final ageing at } 160^{\circ} \mathrm{C} \text { to peak value } \\
\text { f. Quench in water }\end{array}$ \\
\hline TMA IIb & $\mathrm{c}_{\mathrm{d}} \operatorname{mMM}_{\mathrm{e}}$ & $\begin{array}{l}\text { a. As above } \\
\text { b. As above } \\
\text { c. } 50 \text { pct preageing at } 160^{\circ} \mathrm{C} \\
\text { d. } 20 \text { pct warm rolling at } 160^{\circ} \mathrm{C} \\
\text { e. Final ageing at } 160^{\circ} \mathrm{C} \text { to peak value } \\
\text { f. Quench in water }\end{array}$ \\
\hline
\end{tabular}




\section{Results and discussion}

TMA treatments substantially affect the ageing characteristics. TMA Ib treatment yields finest $\theta^{\prime}$ needles having the longitudinal dimension of $\sim 400 \AA$ (figure 1). TMA treatments also lead to dislocation-precipitate networks of different magnitudes. It is observed that TMA IIb treatment results in thickest dislocationprecipitate networks among all the TMA treatments (figure 2). In addition to $\theta^{\prime}$, two

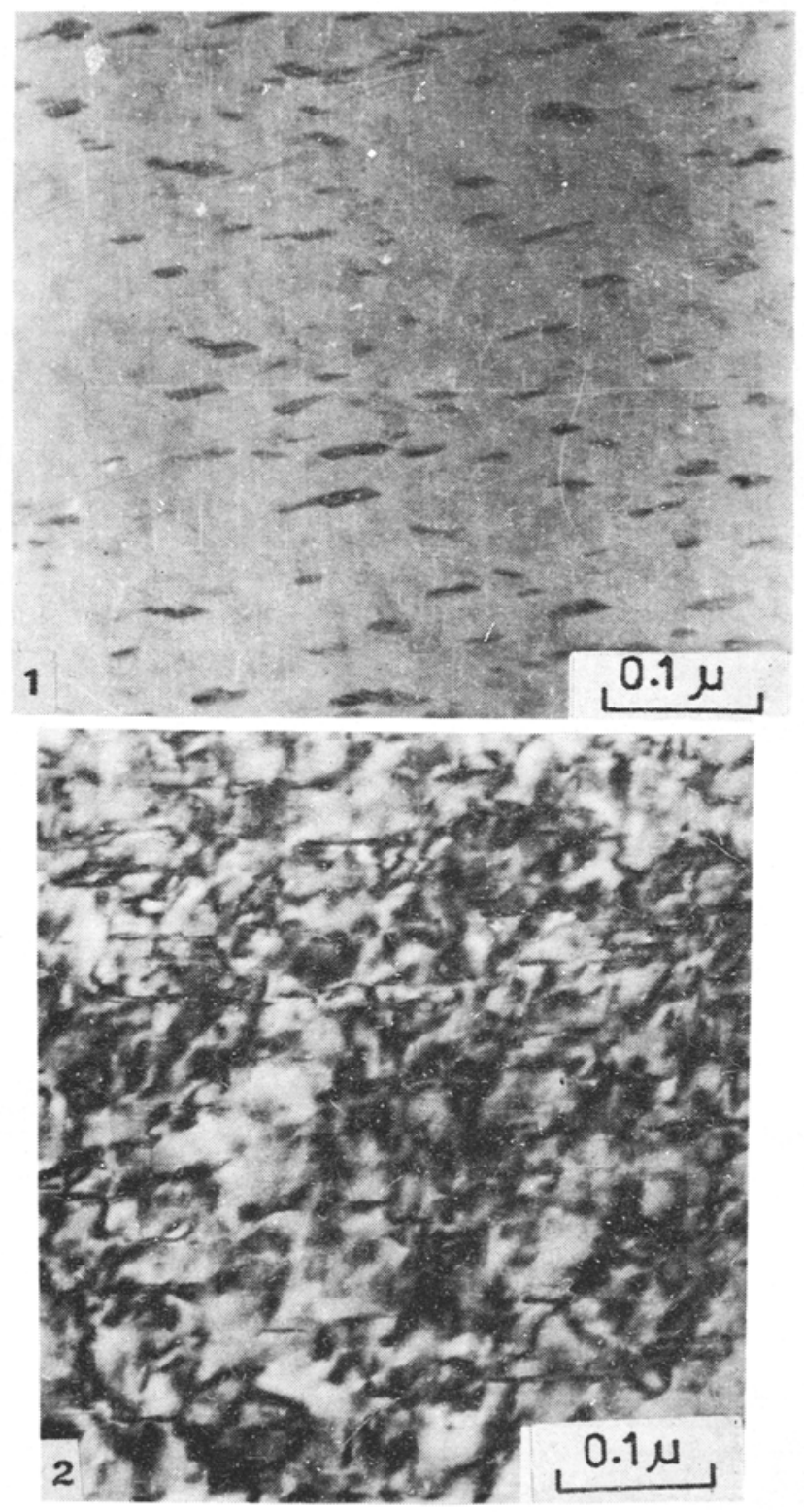

Figures 1 and 2. 1. Fine $\theta^{\prime}$ needles after TMA-Ib treatment. 2. $\theta^{\prime}$-dislocation tangles after TMA-IIb treatment. 
types of dispersoids (Singh 1985) have been observed, identified as $\mathrm{Al}_{4} \mathrm{CuMg}_{5} \mathrm{Si}_{4}$ and $\mathrm{Al}_{12}(\mathrm{Fe}, \mathrm{Mn})_{3} \mathrm{Si}$. The concentration of these dispersoids is drastically reduced as a result of TMA treatment cycles.

TMA treatments significantly affect the various mechanical properties like hardness, tensile properties, fatigue resistance and fracture toughness. Maximum improvement in hardness has been achieved through TMA-IIb treatment (figure 3), which is observed to raise the peak hardness from 114 VHN (achieved under normal ageing condition) to $148 \mathrm{VHN}$ and shorten the time required for the peak to be obtained by $2.50 \mathrm{~h}$.

By optimization of TMA treatment, it is possible to achieve an overall improvement in the mechanical properties (figure 4). Maximum improvement in the properties is observed after TMA-IIb treatment. It is also established that the TMA-IIb treatment not only imparts maximum improvement but also provides maximum stability to tensile properties when exposed to higher working temperatures. The general strengthening of the alloy is attributed mainly to the existence of $\theta^{\prime \prime}, \theta^{\prime}$ and dislocation-precipitate tangles. In the peak-aged material, hardening occurs predominantly due to $\theta^{\prime \prime}$ platelets; whereas after TMA treatments the strengthening at room temperature as well as at elevated temperature is mainly controlled by fine distribution of $\theta^{\prime}$ precipitates and density of dislocations.

The best fatigue properties are observed after TMA-Ib treatment. Fatigue properties improve mainly due to drastic reduction in the concentration of dispersoids and the presence of fine strengthening precipitate $\theta^{\prime}$. The existence of a large number of dispersoids in as-quenched and peak-aged sample is supported by SEM fractographs (figures $5 \mathrm{a}$ and $5 \mathrm{~b}$ ), which explain the poor fatigue properties in these conditions. In addition to their effect on nucleation, dispersoids increase the crack propagation rate by nucleating cracks ahead of the main advancing crack (Ostermann and Reimann 1970; Ruch and Gerold 1982) as shown in figure 5. Fine $\theta^{\prime}$ precipitates lead to better fatigue properties, because they inhibit cross slip and

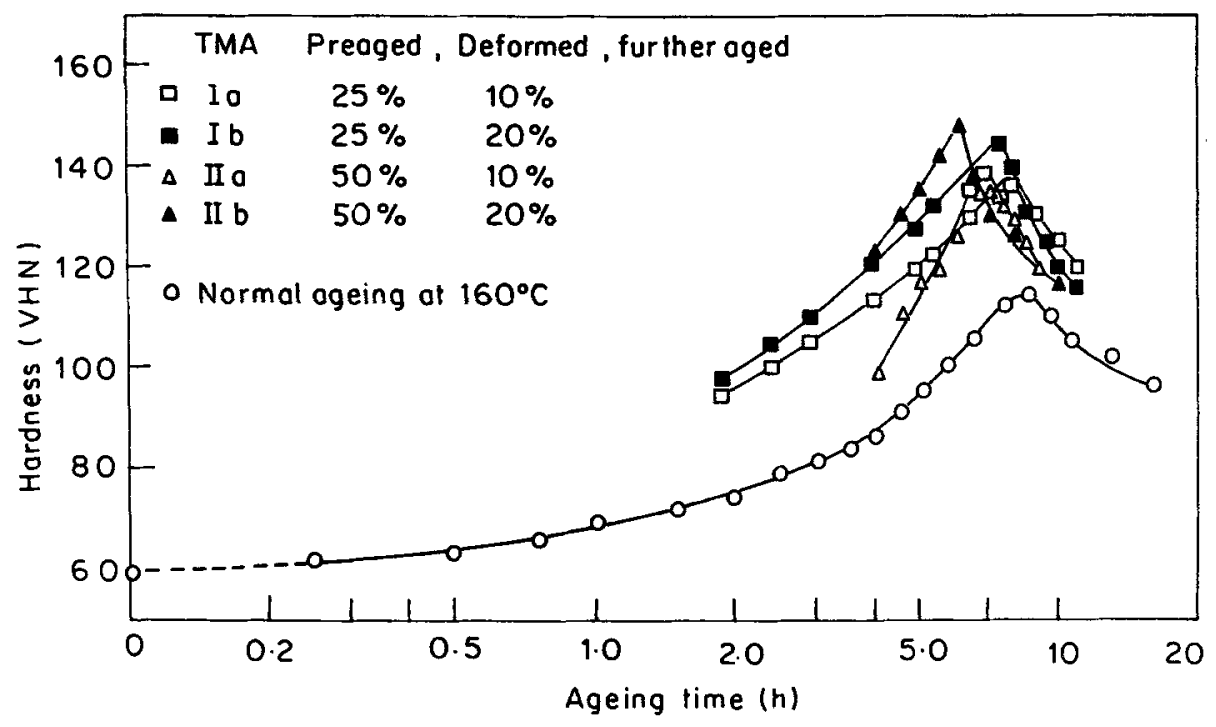

Figure 3. Ageing curves of 2014 Al-alloy after various TMA treatments. 


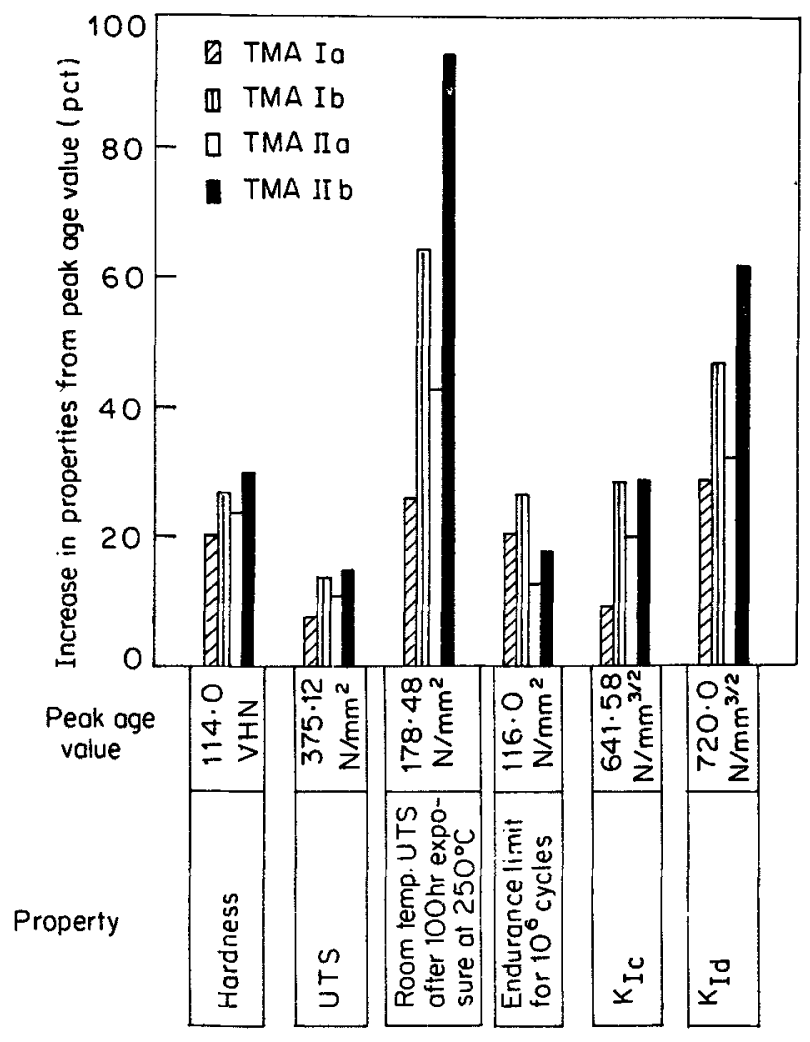

Figure 4. Increase in various properties from peak age value after different TMA treatments.

thus localize the plastic deformation occurring at the crack tip of the advancing front which retards the fatigue crack growth (Ostermann and Reimann 1970; Ruch and Gerold 1982). Maximum improvement in fatigue properties after the TMA-Ib treatment is in agreement with the above discussion. This treatment produces finest distribution of $\theta^{\prime}$ precipitates, lowest density of dispersoids and a relatively uniform dislocation sub-structure.

The present investigation shows that with appropriate choice of thermomechanical treatment, it is possible to improve the fracture toughness properties of 2014 Al-alloy. The various structural parameters, which are likely to affect the fracture toughness of high strength Al-alloys, may be (i) the size, shape and distribution of dispersoids, (ii) size and distribution of strengthening precipitates and (iii) dislocation substructure. It has been shown that dispersoids $(\sim 1-100 \mu)$ can serve as effective crack initiation sites in high strength Al-alloys (Tanaka et al 1970; Hahn and Rosenfield 1975; Rack and Krenzer 1977; Thompson and Levy 1977; Santner 1978). In a recent study Ritchie and Thompson (1985) established that the metallurgical factors which specifically influence yield strength can have a far greater influence on crack growth toughness compared to crack initiation toughness. Thus plane strain fracture toughness $\left(K_{\mathrm{Ic}}\right)$ will be largely governed by the presence of $\theta^{\prime}$ precipitates and dislocation substructure in comparison to dispersoids. In the present investigation the TMA-Ib and TMA-IIb treatments yield 

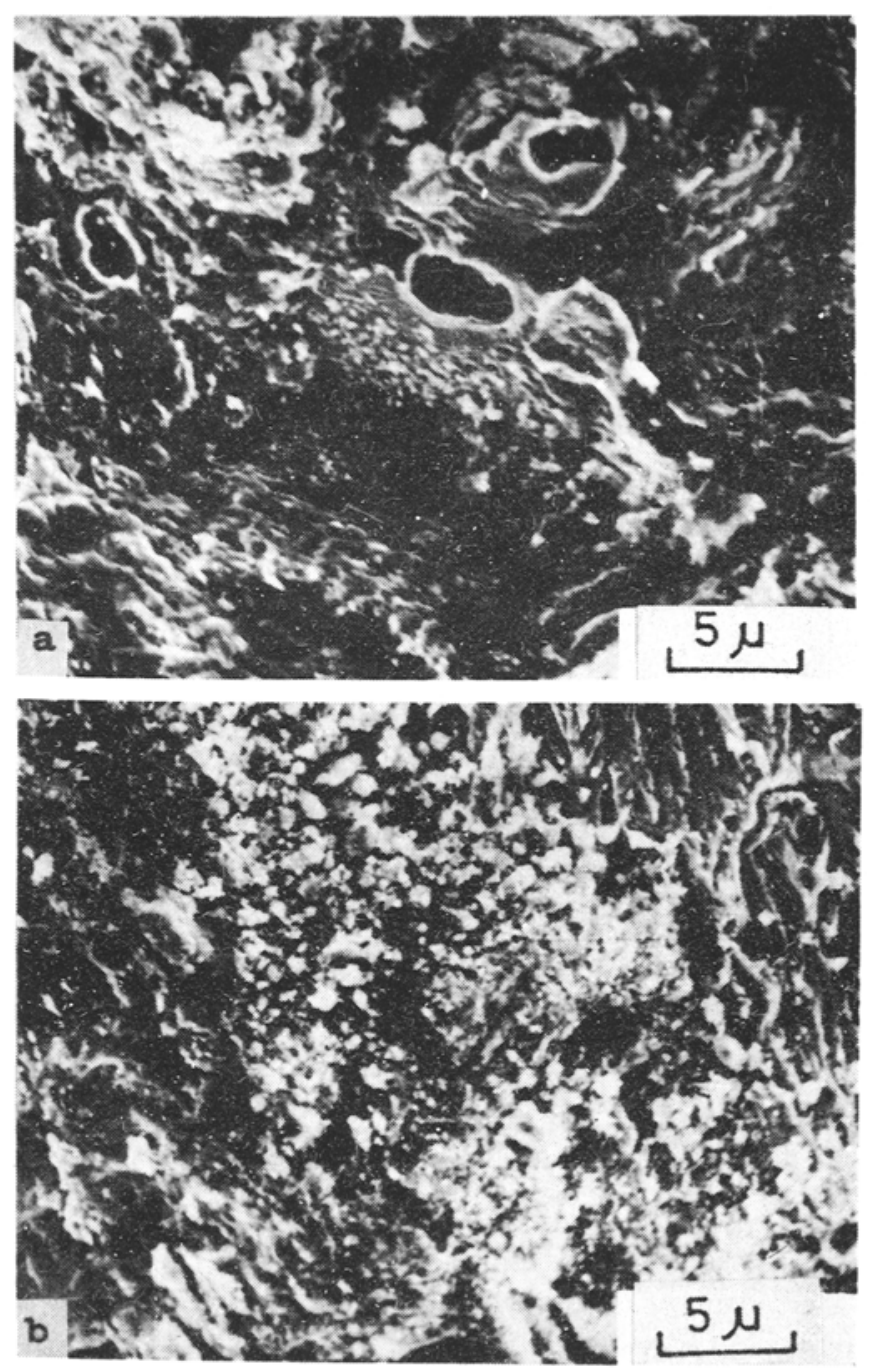

Figure 5. Dispersoids observed on the fracture surface: (a) as-quenched, (b) peak aged.

almost equal improvement in $K_{\mathrm{I}}$ value (figure 4) due to the combined effect of the fineness of $\theta^{\prime}$ and density of dislocations.

In the case of dynamic fracture toughness $\left(K_{\mathrm{Id}}\right)$, due to impact loading instantaneous opening of dispersoid-matrix interfaces takes place and therefore the effect of dispersoids is stronger than in the case of $K_{\mathrm{lc}}$. Since in the case of dynamic fracture toughness the dispersoids also play a major role, the effect of $\theta^{\prime}$ precipitates has to be considered in relation to the space-to-size $(\lambda / d)$ ratio of dispersoids. At very low values of $i / d$, the dispersoids will be close to each other and the concentration of $\theta^{\prime}$ will be very low between the two successive dispersoids. Since, dispersoid-matrix interfaces open up very fast during dynamic loading, the thin layers of $\theta^{\prime}$ will be rather ineffective in controlling coalescence of voids nucleated at various points at the dispersoid-matrix interfaces. At large $\lambda / d$ values, on the other hand, the gaps between dispersoids are large and the concentration of $\theta^{\prime}$ is sufficient 


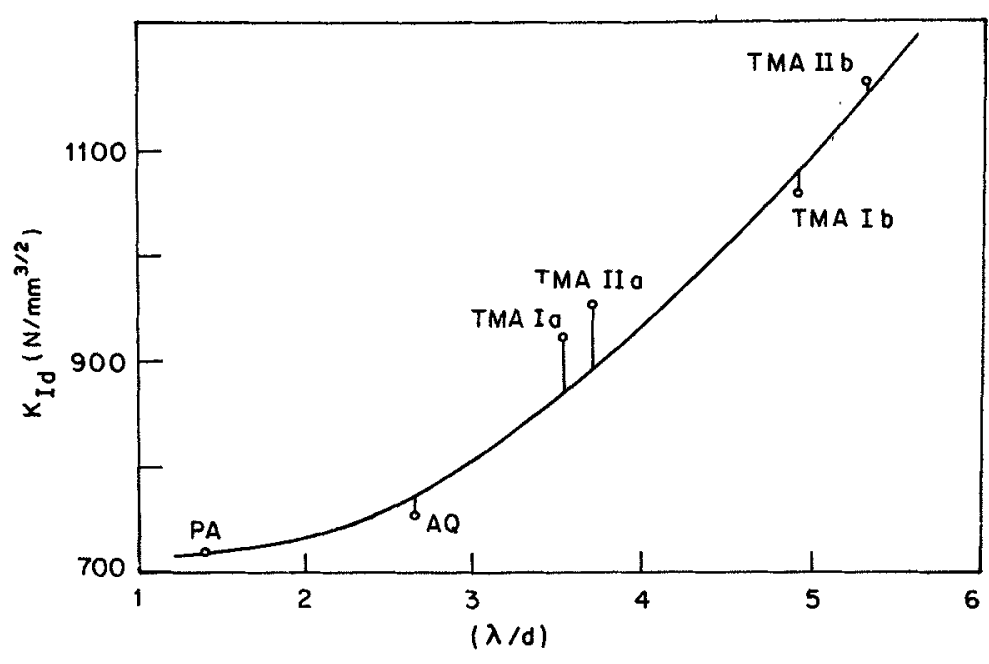

Figure 6. Effect of space-to-size ratio $(\lambda / d)$ of dispersoids on $K_{\mathrm{Id}^{*}}$.

to provide a check on crack growth. In agreement with this discussion the highest value of $\lambda / d(5 \cdot 30)$ is observed in TMA-IIb treatment (figure 6) which shows maximum improvement in $K_{\mathrm{Id}}$ value.

\section{Conclusion}

By a suitable combination of deformation-ageing cycle it is possible to develop an optimized TMA treatment which results in an overall improvement in mechanical properties. Among all the TMA treatments, the TMA-IIb treatment has maximum influence on hardness, $K_{\mathrm{Ic}}, K_{\mathrm{Id}}$ and UTS at room temperature and at elevated temperature. In case of fatigue, this treatment shows somewhat lower values of endurance limit than that obtained in TMA-Ib treatment, which is observed to be the next best TMA treatment.

\section{References}

Di Russo E, Conserva M, Gatto F and Markus H 1973 Met. Trans. A4 1133

Hahn G T and Rosenfield A R 1975 Met. Trans. A6 653

Lipsitt H A 1971 Met. Trans. 2A 1739

Lipsitt H A and Sargent C M 1970 Proc. 2nd Int. Conf. on Strength of Metals and Alloys (Ohio: Metals Park) (ASM) p. 937

Malakondiah G and Rama Rao P 1977 Proc. 4th Int. Conf. on Fracture (ed.) DMR Taplin (Waterloo, Canada) Vol. 2 B p. 741

Ostermann F G and Reimann W H 1970 ASTM STP 467, Am. Soc. Testing Mater. 169

Pattanaik S, Srinivasan V and Bhatia M L 1972 Scr. Metall. 6191

Rack H J and Krenzer R W 1977 Met. Trans. 8A 355

Ritchie R O and Thompson A W 1985 Met. Trans. 16A 233

Ruch W and Gerold V 1982 Proc. 4th ECF Conf. (Leoben, Austria) p. 383

Ryum N 1969 Acta Metall. 17821

Santner J S 1978 Met. Trans. 9A 769

Singh S 1985 Ph.D. Thesis, University of Roorkee, Roorkee

Tanaka J P, Pampillo C A and Low J R Jr. 1970 ASTM STP 463 Am. Soc. Testing Mater. 191

Thompson D S and Levy S A 1977 Light metal age p. 11 